\title{
Prenatal risk factors for autism: comprehensive meta-analysis
}

\author{
Hannah Gardener, Donna Spiegelman and Stephen L. Buka
}

\section{Background}

The aetiology of autism is unknown, although prenatal exposures have been the focus of epidemiological research for over 40 years.

\section{Aims}

To provide the first quantitative review and meta-analysis of the association between maternal pregnancy complications and pregnancy-related factors and risk of autism.

\section{Method}

PubMed, Embase and PsycINFO databases were searched for epidemiological studies that examined the association between pregnancy-related factors and autism. Forty studies were eligible for inclusion in the meta-analysis. Summary effect estimates were calculated for factors examined in multiple studies.

\section{Results}

Over 50 prenatal factors have been examined. The factors associated with autism risk in the meta-analysis were advanced parental age at birth, maternal prenatal medication use, bleeding, gestational diabetes, being first born $v$. third or later, and having a mother born abroad. The factors with the strongest evidence against a role in autism risk included previous fetal loss and maternal hypertension, proteinuria, pre-eclampsia and swelling.

\section{Conclusions}

There is insufficient evidence to implicate any one prenatal factor in autism aetiology, although there is some evidence to suggest that exposure to pregnancy complications may increase the risk.

\section{Declaration of interest}

None.
Autism is a developmental disorder characterised by deficits in social interaction and communication, and restricted, repetitive interests and behaviours beginning in infancy and toddler years. ${ }^{1,2}$ The prevalence of autism has been estimated at 13/10000 and is believed to be rising. ${ }^{3}$ The aetiology is unknown. Although the estimated $60-92 \%$ concordance rate in monozygotic twins as compared with $0-10 \%$ in dizygotic twins underscores the importance of genetic influences, the incomplete concordance in monozygotic twins also indicates a role of environmental factors. $^{4,5}$ It is now believed that the mechanism underlying autism aetiology is most likely polygenic and potentially epistatic and that environmental factors may interact with genetic factors to increase risk. ${ }^{6,7}$

Although the distinctive neuropathology remains elusive, studies have shown macroscopic, microscopic and functional brain abnormalities. ${ }^{6,8}$ These brain abnormalities suggest that the aetiologically relevant period may be in utero because the pathogenesis may begin during the prenatal period. ${ }^{6}$

Pregnancy-related exposures have been the focus of a significant amount of epidemiological research on possible risk factors for autism. Although many studies support the hypothesis that obstetrical complications may increase the risk of autism, ${ }^{9}$ the specific complications, magnitude of effect and overall conclusions of these studies are inconsistent. These inconsistencies may be because of methodological variations including diagnostic criteria, comparison groups, sample size and exposure assessment methods.

The purpose of this study is to provide a systematic review and meta-analysis of the epidemiological literature on the relationship between prenatal complications/exposures and autism. A review article by Kolevson and colleagues discussed seven studies on this topic. ${ }^{9}$ Our study expands upon this review by providing the first formal meta-analysis as well as a quantitative review of all 64 studies of prenatal risk factors for autism published up to March 2007. We review the evidence for all prenatal factors examined in the literature, and provide a summary effect estimate for all factors examined in two or more studies. The scope of literature reviewed allows for meta-regression analyses to examine whether study design characteristics explain the heterogeneity in results across studies.

\section{Method}

\section{Data sources and review methods}

PubMed, Embase, and PsycINFO databases were searched using the keywords 'autism' in combination with 'prenatal' or 'perinatal' or 'pregnancy' or 'neonatal', limited to peer-reviewed studies published in any language through to March 2007. The search identified 698 studies in PubMed, 176 in Embase and 416 in PsycInfo. The literature search sought to identify all epidemiological studies that have examined the association of pregnancy and delivery factors and neonatal complications to the risk of autism. Based on a review of all abstracts, 83 papers were identified as potentially relevant and reviewed further. Those studies that were not reviewed included case series, animal studies, autism prevalence studies, medical hypotheses, studies of other psychiatric diseases (e.g. schizophrenia) and studies of unrelated exposures (e.g. demographics, familial psychiatric diseases, genetics, infant behaviours). Forty-one additional potential papers were identified after screening the reference lists of original and review articles. Among the 124 studies that were reviewed, we excluded those that did not include a comparison group $(n=13)$ or any formal statistical analyses $(n=3)$, did not examine exposures during pregnancy or the first month of life $(n=10)$, grouped their autism cases with other childhood psychotic disorders $(n=15)$ and were review or commentary articles $(n=18)$. The control group had to be non-autistic but could be otherwise affected. In total, 65 studies were eligible for inclusion $^{5,10-73}$ in the quantitative review. Two studies ${ }^{15,30}$ reporting on the same data-set were considered together, resulting in 64 studies for review. 
Although the literature search covered the scope of prenatal, perinatal and neonatal factors, the current report reviews the pregnancy-related factors only, and a future publication will address factors related to labour and delivery as well as neonatal complications in relation to autism. However, it is important to recognise that prenatal, perinatal and neonatal complications are interrelated, and are therefore difficult to disentangle and reliably categorise. Many perinatal and neonatal complications are often the result of both observed and unobserved prenatal insults and compromises to fetal development. This report focuses on those potential risk factors that were commonly identified as being specifically related to the prenatal period in the extant literature.

The first author abstracted each article on two separate occasions spaced 1 year apart. For each study the following information was recorded:

(a) study design (cohort, case-control);

(b) sample size and description (e.g. clinic based, population based);

(c) comparison group description (e.g. matching criteria, sibling controls, healthy $v$. otherwise affected controls, diagnoses of otherwise affected controls);

(d) autism diagnostic criteria and mode of reporting (e.g. DSM-III $v$. DSM-IV, parental report $v$. medical record review $v$. study physician assessment, diagnostic measures used);

(e) risk factors examined and mode of reporting (e.g. parental interview, medical record review);

(f) covariates included in multivariate models;

(g) study results, including indicators of statistical significance, prevalence of exposures among cases and controls, rates or risks of autism across exposure levels, relative risks (RRs) and $95 \%$ confidence intervals (CIs).

Studies were classified as prospective $v$. retrospective if exposures were assessed and recorded before or after the onset of autism, regardless of when they were analysed for the purposes of the given study. For the quantitative review, we counted the number of studies that examined each prenatal factor in relation to the risk of autism and the number of null findings, significant and marginally significant positive findings, significant and marginally significant negative findings.

\section{Statistical analysis}

Meta-analysis

Of the 64 studies reviewed, 40 were appropriate for inclusion in the meta-analysis. ${ }^{10-49}$ Twenty-four studies were excluded from the meta-analysis because they did not report relative risks and confidence intervals or did not provide information needed to calculate them. A separate meta-analysis was conducted for each exposure variable that was examined in two or more studies. For each exposure, a summary effect estimate was calculated using a random-effects model. ${ }^{74}$ Because power to detect heterogeneity is low in meta-analyses such as these, ${ }^{75}$ we took a conservative approach and used random-effects models to form confidence intervals, because random-effects models account for any observed heterogeneity regardless of whether the heterogeneity is statistically significant. When available, the estimate used for each study was the multivariate estimate controlling for the maximum number of covariates.

If an effect estimate was reported without the corresponding 95\% CI, the confidence bounds were derived from the $P$-value provided. If no $P$-value was provided, then a $P$-value of 0.05 or
0.50 was assumed for factors that did and did not reach statistical significance respectively.

Several studies included autism-spectrum disorders in their case definition. Five studies reported results for both the broader phenotype and for narrowly-defined autism, ${ }^{22,25-27,29}$ in which case the study-specific exposure effect estimates using the narrowest diagnostic criteria were recorded.

The relationships between autism and maternal/paternal age at birth as well as birth order were assessed categorically and meta-analytic tests of trend (details available from the authors on request $)^{76}$ were conducted using ordinal categorical variables with the score of each category equal to the mid-point of the exposure range, using SAS version 9 on UNIX (SAS Institute, Cary, NC). These trend tests were restricted to studies that provided information on the number of cases and participants at each exposure level.

As a result of the rarity of many of the exposures and small sample sizes, there were tables in some $(<5 \%)$ of the meta-analyses with zero cell counts. In these instances, 0.5 was added to each cell of the $2 \times 2$ table. $^{77}$

Several studies used multiple control groups (e.g. individuals with intellectual disability (also known as mental retardation) and healthy controls). In these studies, the comparison groups were pooled and compared with the cases as a single group.

Some studies classified the exposures of interest into distinct subcategories (e.g. bleeding by trimester). In addition to providing a summary estimate for the primary exposure of interest (e.g. pregnancy bleeding), we also calculated summary estimates for each subcategory. If only the crude estimates were provided then the exposures were pooled by simply adding the cases-controls who experienced each subcategory type. If multivariate adjusted estimates were provided then the adjusted estimates for each exposure subcategory were combined using the method proposed by Greenland \& Longnecker $^{76}$ to adjust the variance of the summary estimate by accounting for the covariance due to the inclusion of overlapping comparison groups across exposure subcategories.

\section{Meta-regression}

For each risk factor assessed in multiple studies we examined the heterogeneity in the relative risks estimated across studies using the Q statistic. ${ }^{74,78}$ As a result of the limited power of this test ${ }^{75}$ a liberal $P$ of $<0.10$ was used to identify meta-analyses that required further examination to assess potential sources of heterogeneity. If we found evidence of suggested heterogeneity, a meta-regression ${ }^{79,80}$ was conducted to identify measured methodological factors that could explain the between-study variability (i.e. between-study effect modification).

The analyses of effect modification were conducted using the 'metareg' command in Stata 8 on Windows. ${ }^{79}$ The study characteristics that were examined included: diagnostic criteria (inclusion of spectrum disorders: yes $v$. no); exposure information quality (0, retrospective exposure assessment; 1, mix of retrospective and prospective exposure assessment; 2, prospective exposure assessment); control for confounding (0, univariate analysis; 1, control for select demographic factors, birth order, or IQ; 2, full multivariate analysis or matching with sibling controls); normal $v$. abnormal controls; and case selection (clinic based $v$. population based). If effect modification was suggested for a given study characteristic $(P<0.10)$, then a stratified analysis was performed.

Publication bias was assessed for each factor by conducting tests for funnel plot asymmetry ${ }^{81}$ using the 'metabias' command in Stata 8. Two statistical approaches were used to examine the 
association between study size and the effect of the exposure: the Begg test ${ }^{82}$ and the Egger test. ${ }^{83}$

\section{Results}

Table 1 and Table 2 list the prenatal factors that were not included in the meta-analysis due to unavailability of two or more effect estimates and 95\% CIs, as well as an indication of whether they were associated with autism in the studies in which they were examined. Online Table DS1 lists the prenatal factors included in the meta-analyses, as well as the number of null findings, significant and marginally significant positive findings, and significant and marginally significant negative findings (protective association). For each factor that was examined in the metaanalysis, online Table DS1 reports the summary effect estimate and $95 \% \mathrm{CI}$ from the random-effects model, and the $P$-value for the test of heterogeneity.

The meta-analysis found few statistically significant risk factors. Maternal gestational diabetes was associated with a twofold increased risk of autism. In addition, a significant $81 \%$ elevated risk was observed in relation to maternal bleeding during pregnancy. Maternal medication use was also associated with a $46 \%$ increased risk. Although 15 studies examined the relationship between prenatal medication use and risk of autism, the majority studied the general use of any medications during pregnancy, whereas only a few examined the association with specific classes of medications. A meta-analysis of the two studies that looked specifically at psychiatric medication use during pregnancy suggested a significant positive association with the risk of autism $(\mathrm{RR}=1.68)$.

Maternal age at birth over 30 was associated with an increased risk with effect estimates ranging from a $27 \%$ increased risk (3034 v. $25-29)$ to a $106 \%$ increase in risk $(40+v$. $<30)$. Thirteen studies were included in the meta-analyses of maternal age at birth. The trend test included nine studies and indicated a significant increase in risk of autism with increasing maternal age at birth (trend $P=0.02$ ). A 5 -year increase in maternal age was associated with a $7 \%$ increase in risk.
Increased paternal age at birth was also found to be a significant risk factor (trend $P=0.004$ ), with a 5 -year increase in paternal age associated with a $3.6 \%$ increase in risk. Individual exposure category effect estimates ranged from 1.24 (30-39v. $<30)$ to $1.44(40+v .25-29)$. In addition, the three studies that examined the effect of young paternal age at birth indicated a $26 \%$ decrease in risk for paternal age $<25$ v. $25-29$. Only four studies were included in the meta-analyses of paternal age.

Of the nine studies that indicated a significant relationship between birth order/parity and risk of autism, six indicated a mixed trend. Specifically, autism was associated with being first or later born ( $\geqslant$ third), often depending on the size of the sibship. The meta-analysis found a statistically significant $61 \%$ increase in risk for first-born children compared with children born third or later. This meta-analysis included four studies. No significant associations were observed in the comparisons of other birth order categories and the trend test did not indicate a linear relationship between birth order and autism risk.

Maternal birth abroad was marginally associated with risk of autism. In the five studies included in the meta-analysis, maternal birth abroad was associated with a $28 \%$ increased risk $(P=0.06)$. However, the definition of 'abroad' varied as the studies were conducted in different countries and areas of the world. In the studies conducted in Nordic countries, a statistically significant $58 \%$ increased risk of autism was observed among the offspring of mothers born abroad.

Heterogeneity in effect estimates across studies was observed for the following factors $(P<0.10)$ : infections during pregnancy, nausea/vomiting, bleeding, weight gain, maternal age at birth, paternal age at birth $(40+v .<30)$, birth order, smoking during pregnancy, mother born abroad and pre-eclampsia. Table 3 shows the results of the regression analyses that examined the potential between-study sources of heterogeneity.

The analysis of infections during pregnancy indicated significant effect modification based on control for covariates. Exposure to intrauterine infections was associated with a significant increase in risk for autism in the analysis limited to the four studies that controlled for multiple covariates or used sibling controls. However, there was no relationship between infections during

Table 1 Pregnancy-related risk factors examined in only one study and not eligible for meta-analysis

\begin{tabular}{ll} 
Association with autism & Risk factor \\
None & $\begin{array}{l}\text { Chronic maternal disease, maternal cytomegalovirus, autoimmune disease, severe cholecystitis, endocrine diseases, } \\
\text { venous thrombosis, infertility requiring medical intervention, previous live births now dead, frequency of intercourse } \\
\text { during pregnancy, irregular menstrual periods, maternal immunisation, maternal transfusions, previous X-rays, chorionic } \\
\text { villi sampling, amniocentesis, pre-pregnancy body mass index, drug use during pregnancy, fetal oxygenation, maternal } \\
\text { age at first birth 30+, father with foreign citizenship }\end{array}$ \\
\hline Positive & $\begin{array}{l}\text { Maternal asthma, allergies, maternal toxaemia or bleeding, prenatal stressors, month prenatal care began, urbanisation } \\
\text { of birth place }\end{array}$ \\
\hline Negative & Maternal alcohol use during pregnancy
\end{tabular}

Table 2 Pregnancy-related risk factors examined in multiple studies ${ }^{a}$ but not eligible for meta-analysis

\begin{tabular}{ll} 
Prenatal factor (study $n$ ) & Results across studies $^{\text {b }}$ \\
Maternal depression (2) & 2 significant positive* \\
\hline Maternal emotional strain (3) & 2 significant positive* \\
& 1 marginally significant positive ${ }^{* *}$ \\
\hline Maternal psychiatric care (2) & 2 null \\
\hline Contraception use prior to pregnancy (2) & 1 null \\
& 1 significant negative* \\
$\begin{array}{l}\text { a. Although these factors were examined in multiple studies, effect estimates and confidence intervals were available for fewer than two studies. } \\
\text { b. Total number of studies included in the review: } 64 .\end{array}$ \\
${ }^{*} P<0.05, * * 0.10<P<0.05$.
\end{tabular}


Table 3 Analysis of effect modification by study characteristics: prenatal risk factors with heterogeneity $(P<0.10)$

\begin{tabular}{|c|c|c|}
\hline Prenatal risk factors & $\begin{array}{l}\text { Significant sources of between-study heterogeneity: } \\
\text { study characteristics }(P<0.10)^{\mathrm{a}}\end{array}$ & $\begin{array}{l}\text { Summary effect estimate } \\
\qquad(95 \% \mathrm{Cl})\end{array}$ \\
\hline Infections during pregnancy & $\begin{array}{l}\text { Multivariate } v \text {. univariate analysis }(P=0.09) \\
4 \text { studies: controlled for multiple covariates } \\
7 \text { studies: no control for covariates }\end{array}$ & $\begin{array}{l}1.18(0.76-1.83) \\
1.82(1.01-3.30) \\
0.89(0.56-1.42)\end{array}$ \\
\hline Nausea/vomiting & $\begin{array}{l}\text { Exposure data collection }(P=0.004) \\
3 \text { studies: prospective } \\
3 \text { studies: retrospective }\end{array}$ & $\begin{array}{l}1.16(0.65-2.09) \\
1.48(1.03-2.14) \\
0.55(0.31-0.98)\end{array}$ \\
\hline Maternal age: linear trend & None & $1.07(1.01-1.13)$ \\
\hline Birth order: linear trend & None & $0.95(0.89-1.02)$ \\
\hline Smoking during pregnancy & $\begin{array}{l}\text { Population-based }(P=0.06) \\
3 \text { studies: population based } \\
2 \text { studies: clinic based }\end{array}$ & $\begin{array}{l}1.00(0.75-1.36) \\
1.15(0.90-1.47) \\
0.63(0.37-1.08)\end{array}$ \\
\hline Mother born in another country & None & $1.28(0.99-1.65)$ \\
\hline Bleeding & None & $1.81(1.14-2.86)$ \\
\hline Toxaemia/pre-eclampsia, hypertension, swelling & None & $1.01(0.80-1.27)$ \\
\hline
\end{tabular}

pregnancy and autism in the studies that did not control for covariates or use sibling controls. For nausea/vomiting, there was significant effect modification based on whether the exposure was assessed prospectively or retrospectively. The positive relationship between nausea/vomiting and autism was only significant among prospective studies ( $\mathrm{RR}=1.48,95 \% \mathrm{CI} 1.03-2.14$ ). In fact, the meta-analysis restricted to the three retrospective studies that examined nausea/vomiting in relation to autism suggested a protective association ( $\mathrm{RR}=0.55,95 \%$ CI $0.31-0.98$ ).

The test for linear trend in birth order indicated significant heterogeneity across studies that could not be explained by variation in any of the study characteristics examined. The analyses of several maternal age at birth comparisons as well as the linear trend test also indicated heterogeneity in the effect estimates across studies. Variation in the methodological characteristics could not explain the heterogeneity in the trend estimates. However, heterogeneity in the effect estimates for the maternal age categorical comparisons may have been as a result of the control for covariates. In general, the elevation in risk observed in relation to older maternal age at birth was slightly attenuated in the studies that controlled for multiple covariates.

Heterogeneity in the effect estimates for maternal smoking during pregnancy may have been as a result of the study base (population based or clinic based). No significant relationship with autism was observed overall or within strata, although only five studies were included in this meta-analysis.

Lastly, for the analyses of toxaemia/pre-eclampsia (17 studies), maternal birth abroad ( 5 studies) and bleeding (13 studies), the heterogeneity of effect estimates across studies could not be explained by any of the study characteristics investigated.

Publication bias was assessed for all factors examined in three or more studies. Significant publication bias was only suggested for smoking during pregnancy (Begg's test $P=0.03$, Egger's test $P=0.04)$. The test for publication bias for prenatal smoking in fact indicated a potential bias in the direction of publishing inverse associations, as suggested by the fact that the three (out of five) smaller studies in the meta-analysis all reported relative risks that were below the null. Both of the tests for publication bias lacked power because of the small number of studies included in each meta-analysis. ${ }^{84}$ However, as a result of the many tests of publication bias performed it is likely that we would observe one or more significant results due to chance alone.
Several studies examined the relationship between compromised prenatal health in general and risk of autism, although none provided the necessary data for inclusion in the meta-analysis. Specifically, six studies utilised prenatal optimality scales to assess the number of prenatal complications experienced in cases and controls (Gillberg Optimality Scale, ${ }^{55,61}$ modified Gillberg Optimality Scale, ${ }^{41,53}$ Lewis-Murray Scale, ${ }^{44}$ Rochester Research Obstetrical Scale ${ }^{60}$ ). Four of these studies reported a significant association between reduced prenatal optimality and risk of autism. ${ }^{53,55,60,61}$

\section{Discussion}

This study is the first meta-analysis of the relationship between prenatal factors and risk of autism. Over 50 prenatal factors have been studied in relation to autism in 64 epidemiological studies, of which 40 were eligible for meta-analysis. However, few factors have been examined in multiple well-conducted studies. Therefore, attempted replication in methodologically strong studies remains necessary. Although the majority of factors examined in multiple studies have given inconsistent results, the preponderance of findings overall have not been statistically significant. The factors with the strongest evidence for an association with autism risk included advanced maternal and paternal age at birth, maternal gestational bleeding, gestational diabetes, being first born $v$. third or later, maternal prenatal medication use and maternal birth abroad. The factors with the strongest evidence against a role in autism risk included previous fetal loss and maternal pre-eclampsia, proteinuria, hypertension and swelling.

Although there is insufficient evidence to implicate any one prenatal factor in autism aetiology, the studies using prenatal optimality scales provide some evidence to suggest that exposure to pregnancy complications in general may increase the risk of autism. It is also important to note that the aetiological importance of the prenatal period may not be fully captured by examining only those complications and characteristics that are manifested and observed during the period of gestation. Many perinatal and neonatal complications also reflect what was occurring during pregnancy, and it may be that only those compromises to the prenatal environment that are manifested in labour and delivery as well as neonatal health complications are 
aetiologically relevant. The potential effects of a non-optimal prenatal environment as manifested in perinatal and neonatal complications will be addressed in our subsequent manuscript on this topic.

\section{Parental age}

The current meta-analysis shows that increased maternal and paternal age at birth are both associated with an elevated risk of autism. The biological mechanisms underlying these relationships are not known. Maternal age may be associated with autism because of the increased risk of chromosomal abnormalities in ova of increased age or as a result of unstable trinucleotide repeats. ${ }^{9}$ Although advanced maternal age has been shown to be associated with an increased risk of obstetrical complications, ${ }^{85,86}$ it is unknown which, if any, of these complications may affect the risk of autism. Reichenberg et $a l^{42}$ suggested that the relationship between paternal age and autism may be because of imprinted genes, de novo spontaneous mutations that accumulate with advancing age in spermatagonia or confounding by sociocultural environmental factors. Maternal and paternal age at birth are likely correlated ${ }^{87,88}$ and many of the studies included did not adjust paternal age for maternal age and vice versa. It is possible that advanced age of both parents plays a role in the susceptibility to autism or perhaps only maternal age or paternal age is aetiologically relevant. There is evidence to suggest that paternal age may be more important. Of the four studies that controlled for the age of the co-parent, three found only a significant association for paternal age at birth, ${ }^{33,34,42}$ and one found only a significant association for maternal age. ${ }^{38}$ When the analysis of maternal age was restricted to the four studies that controlled for paternal age the relative risk for a 5 -year increase in maternal age was $1.06(P=0.08)$. All studies of paternal age included in the meta-analysis were adjusted for maternal age.

\section{Birth order}

Perhaps the factor that was most commonly associated with the risk of autism in the literature was birth order. Nine studies reported a significant relationship between birth order/parity and autism. However, the nature of the relationship was inconsistent across studies and was generally not found to be linear. The difficulty in elucidating the relationship between birth order/parity and autism may be as a result of potential effect modification by sibship size, as individuals with autism are more likely to be first-born in sibship sizes of two and later-born in families with larger sibship sizes. ${ }^{61,69}$ The latter trend has been attributed to parents deciding not to have additional children after one has developed autism. ${ }^{89}$

\section{Maternal birth abroad}

Maternal immigration has also been highlighted as a potential risk factor for autism. ${ }^{9}$ In the meta-analysis, the elevated risk of autism among the offspring of women born abroad was just shy of statistical significance. In the three studies conducted in Nordic countries there was a significant $58 \%$ increased risk among the offspring of mothers born abroad, although the definition and categorisation of 'abroad' differed across the studies. The strength of the association in the Nordic studies may be because of an unknown mechanism particular to this area, or, perhaps more likely, may have been as a result of the methodological strengths of these three studies.

Several hypotheses have been postulated, including the idea that fathers with social disability potentially as a result of a genetic mechanism associated with autism may be less able to find a spouse from their own country and may therefore find a wife from a foreign country with whom to have children. ${ }^{90}$ More likely, Gillberg et al ${ }^{90}$ suggested that women born in another country may not be immunised against the common infectious agents in the country in which she gives birth and may therefore be more susceptible to relatively innocuous infections that may increase the risk for autism. Other possible explanations include a potential role of maternal stress because of the demands of residing in a new country, particularly with limited social support, or stress resulting from the experience of emigrating, perhaps as a result of economic or social factors. These hypotheses do not explain the relationship with maternal place of birth seen in a cohort study of children born in California between 1989 and 1994, ${ }^{16}$ which showed a $40 \%$ decreased risk of autism among the children of women born in Mexico as compared with California. The association between maternal immigration and autism risk requires further examination in other areas of the world to examine whether the relationship can truly be generalised.

\section{Gestational bleeding}

Fetal hypoxia may underlie a potential relationship between gestational bleeding and autism. Maternal bleeding is one of several complications believed to be associated with fetal hypoxia. ${ }^{9}$ Fetal distress, maternal hypertension, prolonged labour, cord complications, low Apgar score and Caesarean delivery are other pregnancy-related factors that are believed to be related to hypoxia and have been associated with autism risk in some, but not all, studies. Although some brain abnormalities observed in individuals with autism may reflect a potential role of oxygen deprivation during development, this possibility requires further examination. Hypoxia has also been shown to increase dopaminergic activity, and there is evidence for dopamine overactivation in autism. ${ }^{91}$

Bleeding in the second half of pregnancy in particular may reflect severe complications including placenta praevia or abruptio placenta. ${ }^{29}$ Although the analyses stratified by trimester did not produce significant associations, only two studies were available to calculate the trimester-specific estimates.

\section{Gestational diabetes}

A biological mechanism underlying the potential elevated risk of autism associated with gestational diabetes is unknown. Gestational diabetes has been associated with various adverse pregnancy outcomes, ${ }^{92-94}$ and the hormonal and metabolic abnormalities and oxidative stress because of gestational diabetes may have lasting consequences for offspring health and development. ${ }^{92,95}$ It is possible that the reported increasing maternal and paternal age at birth and rate of gestational diabetes may be contributing factors to the rising prevalence of autism. ${ }^{96}$

\section{Medication use}

The mechanism underlying the suggested association with maternal medication use is also unclear because of the variety of medications consumed during pregnancy and assessed in these studies. Although many medications may cross the placenta and affect fetal development, the current analysis cannot indicate which medications may be detrimental. However, the meta-analysis of two studies that looked at psychiatric medication use suggested a significant $68 \%$ increased risk of autism, and one small Croatian study $^{32}$ suggested a higher frequency of hormone use among the mothers of individuals with autism than among the mothers of controls with intellectual disability (mental retardation). Maimburg \& Vaeth ${ }^{38}$ found a $50 \%$ increased risk of autism associated with maternal use of medicine in a population-based case-control study using Danish national registries. Although they 
observed no significant association for anti-epileptics, antihypertensives, cardiovascular drugs, tocolytics, nor use of steroids, a significant $60 \%$ increased risk of autism was observed in relation to use of psychoactive drugs. The association with maternal use of psychoactive drugs may reflect either an effect of the medication exposure, an adverse effect of the actual treated condition itself on fetal development (confounding by indication) or transmission of genetic traits possibly shared between autism and other psychiatric disorders.

\section{Non-causal hypotheses}

Investigators have questioned the causal nature of the observed relationship between prenatal complications and autism. Confounding by birth order has been suggested, as an increased risk of autism and obstetrical complications are often observed in first-, fourth- and later-born offspring. ${ }^{52,73}$ Although some studies have shown that associations were attenuated and no longer significant after adjusting for parity, ${ }^{41,61}$ other studies have shown that the positive relationship persists. ${ }^{52,73}$ A second noncausal hypothesis is that obstetrical complications occur as a result of the autistic condition in the offspring or as a consequence of other factors (e.g. genetic factors) that are the true causal determinants of autism. ${ }^{52}$ In this epiphenomena explanation, pregnancy complications simply reflect the abnormalities of autistic fetal development, or the same familial factors cause both autism and obstetrical complications. The study conducted by Bolton et al ${ }^{52}$ provided strong evidence in support of the shared risk hypothesis, as there was an association between obstetric suboptimality and measures of autism severity and familiality and the obstetric suboptimality scores in the individuals with autism were highly correlated with that of their affected siblings. In addition, probands with increased obstetric complications had more extended family members with the broader autism phenotype, although this finding was not replicated in a second study by Zwaigenbaum et al. ${ }^{73}$ The shared risk hypothesis was also supported by the findings in the Zwaigenbaum et al study that indicated more obstetric adversity among unaffected siblings of children with pervasive developmental disorders that had high familial loading for the broader autism phenotype. $^{73}$

\section{Limitations}

Methodological limitations that have impaired the precision and validity of results include small sample size, otherwise affected control groups (e.g. Down syndrome), broad disease definition, and retrospective parental recall of exposures. Of the 64 studies included in the review, only 19 had over $80 \%$ power to detect a relative risk of 2 for an exposure with $10 \%$ prevalence. Nineteen of the studies used broad diagnostic criteria resulting in the possible inclusion of individuals with other autism-spectrum disorders, which may limit the ability to detect associations due to aetiological heterogeneity. Twenty-one studies assessed the exposure variables retrospectively resulting in the high possibility of recall bias. However, the use of medical records also has the limitation of being incomplete. Lastly, the majority of studies included only univariate analyses and did not assess potential confounding. These methodological weaknesses were also likely sources of heterogeneity of effects across studies. Although significant heterogeneity was observed for few factors, the test of heterogeneity lacked power because the majority of the metaanalyses conducted were able to include fewer than six studies and therefore variability in study characteristics was lacking.

This meta-analysis has a few limitations. First, only published data were used. Second, of the 64 studies reviewed, only 40 reported the data necessary for inclusion in the meta-analysis.
Within these 40 studies the investigators did not report the necessary data for a meta-analysis on all factors examined. Although 40 studies were included in the meta-analysis overall, for each factor there were generally fewer than six studies included, limiting the statistical power to detect heterogeneity across studies and potential effect modification by study characteristics. Third, as a result of the rarity of many of the exposures examined and the small sample sizes in many studies, there were instances of zero cell counts within studies. The relatively small addition of 0.5 to the cell counts may have had an impact on the overall results because of the small sample sizes. Fourth, a few studies only reported an effect estimate and an indication of whether the results were statistically significant. In these cases, the confidence intervals were estimated based on assumptions regarding the actual $P$-value $(P=0.05$ if significant, $P=0.50$ if not significant). In the case of statistically significant findings, these assumptions resulted in conservative estimates of the true confidence intervals. Fifth, the tests of publication bias were underpowered because of the limited number of studies in each meta-analysis. Lastly, many studies simply examined all available prenatal data using designs with methodological weaknesses and without a priori hypotheses or knowledge about reproductive epidemiology. As a result, significant associations observed because of chance are possible in this meta-analysis.

The current review and meta-analysis was not restricted to studies with particular methodological strengths. In addition, individual study characteristics were examined in metaregressions rather than assigning studies aggregate quality scores. These strategies are consistent with the recommendations proposed by the 'Meta-Analysis of Observational Studies in Epidemiology Group' that advocated the use of broad inclusion criteria for studies along with regression analyses to relate specific study design characteristics to outcome. ${ }^{97}$ This maximises the amount of data available for review. In addition, different methodological considerations are relevant for each exposure. However, the increased probability for heterogeneity of results using the broad inclusion criteria is important to note.

Twin studies and family aggregation studies have provided clear evidence for the important role of genetics in autism aetiology. ${ }^{6}$ The difficulty in identifying environmental risk factors is likely a result of the complex interactions between these factors and genetics in determining disease susceptibility and the methodological considerations detailed above. Future investigations of prenatal exposures should also collect DNA to study potential gene-environment interactions.

Autism is a devastating condition with no known cure. The rising prevalence, coupled with the severe emotional and financial impact on the families, underscores the need for large, prospective, population-based studies with the goal of elucidating the modifiable risk factors, particularly those during the prenatal period.

\section{Hannah Gardener, SCD, Department of Epidemiology, Harvard School of Public Health, Boston, Massachusetts, Donna Spiegelman, SCD, Departments of Epidemiology and Biostatistics, Harvard School of Public Health, Boston, Massachusetts, Stephen L. Buka, SCD, Department of Community Health, Brown University, Providence, Rhode Island, USA}

Correspondence: Hannah Gardener, Department of Neurology, University of Miami Miller School of Medicine, Post Office Box 016960 (M712), Miami, FL 33101, USA. Email: hgardener@med.miami.edu

First received 22 Feb 2008, final revision 29 Sep 2008, accepted 9 Dec 2008

\section{Funding}

H.G. received a National Research Service Award grant from the Training Program in Psychiatric Epidemiology and Biostatistics (T32 MH17119). Partial funding was provided by the Stanley Medical Research Institute. 


\section{Acknowledgements}

We thank Ruifeng Li, MS (Harvard School of Public Health, Department of Biostatistics) for providing additional statistical and programming support. We also thank Alberto Ascherio, MD, DrPH (Harvard School of Public Health, Departments of Epidemiology and Nutrition; Channing Laboratory, Department of Medicine, Brigham and Women's Hospital and Harment of Epidemiology; Harvard Medical School) for their help and guidance in reviewing the results and manuscript. We thank Dr. Tatjana Rundek, Yueh-Hsiu Mathilda Chiu, and Han dan Wand for their translations of articles published in languages other than English.

\section{References}

1 American Psychiatric Association. Diagnostic and Statistical Manual of Mental Disorders (4th edn, text revision) (DSM-IV-TR). APA, 2000.

2 Ozonoff S, Goodlin-Jones BL, Solomon M. Evidence-based assessment of autism spectrum disorders in children and adolescents. I Clin Child Adolesc Psychol 2005; 34: 523-40.

3 Fombonne E. The changing epidemiology of autism. J Appl Res Intellect Disabil 2005; 18: 281-94.

4 Klauck SM. Genetics of autism spectrum disorder. Eur J Hum Genet 2006; 14 714-20

5 Bailey A, Le Couteur A, Gottesman I, Bolton P, Simonoff E, Yuzda E, et al. Autism as a strongly genetic disorder: evidence from a British twin study. Psychol Med 1995; 25: 63-77.

6 Newschaffer CJ, Fallin D, Lee NL. Heritable and noninheritable risk factors for autism spectrum disorders. Epidemiol Rev 2002; 24: 137-53.

7 Santangelo SL, Tsatsanis K. What is known about autism: genes, brain, and behavior. Am J Pharmacogenomics 2005; 5: 71-92.

8 Dicicco-Bloom E, Lord C, Zwaigenbaum L, Courchesne E, Dager SR, Schmitz $C$, et al. The developmental neurobiology of autism spectrum disorder J Neurosci 2006; 26: 6897-906.

9 Kolevson A, Gross R, Reichenberg A. Prenatal and perinatal risk factors for autism: a review and integration of findings. Arch Pediatr Adolesc Med 2007; 161: 326-33.

10 Akçakin M, Polat S. A comparison of demographic and birth-related characteristics of autistic and intellectually handicapped children. Türk Psikiyatri Dergisi 1993; 4: 39-46.

11 Badawi N, Dixon G, Felix JF, Keogh JM, Petterson B, Stanley FJ, et al. Autism following a history of newborn encephalopathy: more than a coincidence? Dev Med Child Neurol 2006; 48: 85-9.

12 Barak Y, Ring A, Sulkes J, Gabbay U, Elizur A. Season of birth and autistic disorder in Israel. Am J Psychiatry 1995; 152: 798-800.

13 Bolton $\mathrm{P}$, Pickles A, Harrington R, Macdonald H, Rutter M. Season of birth: issues, approaches and findings for autism. J Child Psychol Psychiatry 1992 33: $509-30$.

14 Brimacombe $\mathrm{M}$, Ming $\mathrm{X}$, Lamendola $\mathrm{M}$. Prenatal and birth complications in autism. Matern Child Health J 2007; 11: 73-9.

15 Burd L, Severud R, Kerbeshian J, Klug MG. Prenatal and perinatal risk factors for autism. J Perinat Med 1999; 27: 441-50.

16 Croen L, Grether J, Selvin S. Descriptive epidemiology of autism in a California population: who is at risk? J Autism Dev Disord 2002; 32: 217-24.

17 Croen LA, Grether JK, Yoshida CK, Odouli R, Van de Water J. Materna autoimmune diseases, asthma and allergies, and childhood autism spectrum disorders: a case control study. Arch Pediatr Adolesc Med 2005; 159: 151-7.

18 Croen LA, Yoshida CK, Odouli R, Newman TB. Neonatal hyperbilirubinemia and risk of autism spectrum disorders. Pediatrics 2005; 115: e135-8.

19 Cryan E, Byrne M, O'Donovan A, O'Callaghan E. Brief report: a case-control study of obstetric complications and later autistic disorder. J Autism Dev Disord 1996; 26: 453-60.

20 Deykin EY MacMahon B. Viral exposure and autism. Am J Epidemiol 1979; 109: 628-38.

21 Deykin EY MacMahon B. Pregnancy, delivery, and neonatal complications among autistic children. Am J Dis Child 1980; 134: 860-4.

22 Eaton WW, Mortensen PB, Thomsen PH, Frydenberg M. Obstetric complications and risk for severe psychopathology in childhood. J Autism Dev Disord 2001; 31: 279-85.

23 Finegan J, Quarrington B. Pre-, peri-, and neonatal factors and infantile autism. J Child Psychol Psychiatry 1979; 20: 119-28.

24 Gillberg C Maternal age and infantile autism. J Autism Dev Disord 1980; 10 293-7.

25 Gillberg C. Do children with autism have March birthdays? Acta Psychiatr Scand 1990; 82: 152-6.
26 Glasson EJ, Bower C, Petterson B, de Klerk N, Chaney G, Hallmayer JC. Perinatal factors and the development of autism. Arch Gen Psychiatry 2004; 61: $618-27$

27 Guillem P, Cans C, Guinchat V, Ratel M, Jouk P. Trends, perinatal characteristics, and medical conditions in pervasive developmental disorders. Dev Med Child Neurol 2006; 48: 896-900.

28 Hultman $\mathrm{CM}$, Sparen $\mathrm{P}$, Cnattingius S. Perinatal risk factors for infantile autism. Epidemiology 2002; 13: 417-23.

29 Juul-Dam N, Townsend J, Courchesne E. Prenatal, perinatal, and neonatal factors in autism, pervasive developmental disorder-not otherwise specified, and the general population. Pediatrics 2001; 107: 63-8.

30 Klug MG, Burd L, Kerbeshian J, Benz B, Martsolf JT. A comparison of the effects of parental risk markers on pre- and perinatal variables in multiple patient cohorts with fetal alcohol syndrome, autism, Tourette syndrome, and sudden infant death syndrome: an enviromic analysis. Neurotoxicol Teratol 2003; 25: 707-17

31 Knobloch $\mathrm{H}$, Pasamanick B. Some etiologic and prognostic factors in early infantile autism and psychosis. Pediatrics 1975; 55: 182-91.

32 Kocijan-Hercigonja D, Remeta D, Orehovac M, Brkljacic D. Prenatal, perinatal and neonatal factors in infantile autism. Acta Med Croatica 1991; 45: 357-62.

33 Larsson HJ, Eaton WW, Madsen KM, Vestergaard M, Olesen AV, Agerbo E, et al. Risk factors for autism: Perinatal factors, parental psychiatric history, and socioeconomic status. Am J Epidemiol 2005; 161: 916-25.

34 Lauritsen MB, Pedersen CB, Mortensen PB. Effects of familial risk factors and place of birth on the risk of autism: a nationwide register-based study. $J$ Child Psychol Psychiatry 2005; 46: 963-71.

35 Laxer G, Rey M, Ritvo ER. A comparison of potentially pathologic factors in European children with autism, Down Syndrome, and multiple physical handicaps. J Autism Dev Disord 1988; 18: 308-14.

36 Levy S, Zoltak B, Saelens T. A comparison of obstetrical records of autistic and nonautistic referrals for psychoeducational evaluations. J Autism Dev Disord 1988; 18: 573-81.

37 Lobascher ME, Kingerlee PE, Gubbay SS. Childhood autism: an investigation of aetiological factors in twenty-five cases. Br J Psychiatry 1970; 117: 525-9.

38 Maimburg RD, Vaeth M. Perinatal risk factors and infantile autism. Acta Psychiatr Scand 2006; 114: 257-64.

39 Mason-Brothers A, Ritvo ER, Pingree C, Petersen PB, Jenson WR, McMahon WM, et al. The UCLA-University of Utah epidemiologic survey of autism: prenatal, perinatal, and postnatal factors. Pediatrics 1990; 86: 514-9.

40 Matsuishi T, Yamashita Y, Ohtani Y, Ornitz E, Kuriya N, Murakami Y, et al. Brief report: incidence of and risk factors for autistic disorder in neonatal intensive care unit survivors. J Autism Dev Disord 1999; 29: 161-6.

41 Piven J, Simon J, Chase GA, Wzorek M, Landa R, Gayle J, et al. The etiology of autism: pre-, peri-, and neonatal factors. J Am Acad Child Adolesc Psychiatry 1993; 32: 1256-63.

42 Reichenberg A, Bresnahan M, Rabinowitz J, Lubin G, Davidson M. Advancing paternal age and autism. Arch Gen Psychiatry 2006; 63: 1026-32.

43 Soldin OP, Lai S, Lamm SH, Mosee S. Lack of a relation between human neonatal thyroxine and pediatric neurobehavioral disorders. Thyroid 2003; 13: $193-8$.

44 Stein D, Weizman A, Ring A, Barak Y. Obstetric complications in individuals diagnosed with autism and in healthy controls. Compr Psychiatry 2006; 47: 69-75.

45 Sugie $Y$, Sugie $H$, Fukuda T, Ito $M$. Neonatal factors in infants with Autistic Disorder and typically developing infants. Autism 2005; 9: 487-94.

46 Tanoue $\mathrm{Y}$, Oda S, Asano F, Kawashima K. Epidemiology of infantile autism in Southern Ibaraki, Japan: differences in prevalence in birth cohorts. J Autism Dev Disord 1988; 18: 155-66.

47 Ward AJ. A comparison and analysis of the presence of family problems during pregnancy of mothers of 'autistic' children and mothers of normal children. Child Psychiatry Hum Dev 1990; 20: 279-88.

48 wier ML, Yoshida CK, Odouli R, Grether JK, Croen LA. Congenital anomalies associated with autism spectrum disorders. Dev Med Child Neurol 2006; 48 : 500-7.

49 Williams G, Oliver JM, Allard A, Sears L. Autism and associated medical and familial factors: a case control study. J Dev Phys Disabil 2003; 15: 335-49.

50 Atladottir HO, Parner ET, Schendel D, Dalsgaard S, Thomsen PH, Thorsen P. Variation in incidence of neurodevelopmental disorders with season of birth. Epidemiology 2007; 18: 240-5.

51 Beversdorf DQ, Manning SE, Hillier A, Anderson SL, Nordgren RE, Walters SE, et al. Timing of prenatal stressors and autism. J Autism Dev Disord 2005; 35 471-8. 
52 Bolton PF, Murphy M, Macdonald H, Whitlock B, Pickles A, Rutter M Obstetric complications in autism: consequences or causes of the condition? J Am Acad Child Adolesc Psychiatry 1997; 36: 272-81.

53 Bryson SE, Smith IM, Eastwood D. Obstetrical suboptimality in autistic children. J Am Acad Child Adolesc Psychiatry 1988; 27: 418-22.

54 Deb S, Prasad KBG, Seth $\mathrm{H}$, Eagles JM. A comparison of obstetric and neonatal complications between children with autistic disorder and their siblings. J Intellect Disabil Res 1997; 41: 81-6.

55 Gillberg C, Gillberg IC. Infantile autism: a total population study of reduced optimality in the pre-, peri-, and neonatal period. J Autism Dev Disord 1983 13: $153-66$.

56 Harper J, Williams S. Early environmental stress and infantile autism. Med J Aus 1974; 1: 341-6.

57 Hazlett HC, Poe M, Gerig G, Smith RG, Provenzale J, Ross A, et al. Magnetic resonance imaging and head circumference study of brain size in autism: birth through age 2 years. Arch Gen Psychiatry 2005; 62: 1366-76.

58 Konstantareas MM, Hauser P, Lennox C, Homatidis S. Season of birth in infantile autism. Child Psychiatry Hum Dev 1986; 17: 53-65.

59 Li S, Yang X, Jia M. A study of perinatal risk factors in patients with autism. Chin J Psychiatry 1998; 31: 178-80.

60 Links PS, Stockwell M, Abichandani F, Simeon J. Minor physical anomalies in childhood autism. Part I. Their relationship to pre-and perinatal complications. J Autism Dev Disord 1980; 10: 273-85.

61 Lord C, Mulloy C, Wendelboe M, Schopler E. Pre- and perinatal factors in high-functioning females and males with autism. J Autism Dev Disord 1991; 21: 197-209.

62 Mouridsen SE, Nielsen S, Rich B, Isager T. Season of birth in infantile autism and other types of childhood psychoses. Child Psychiatry Hum Dev 1994; 25 31-43.

63 Mouridsen SE, Rich B, Isager T. Brief report: parental age in infantile autism, autistic-like conditions, and borderline childhood psychosis. J Autism Dev Disord 1993; 23: 387-96.

64 Park RJ, Bolton PF. Pervasive developmental disorder and obstetric complications in children and adolescents with tuberous sclerosis. Autism 2001; 5: 237-48.

65 Steffenberg S, Gillberg C, Hellgren L, Andersson L, Gillberg IC, Jakobsson G, et al. A twin study of autism in Denmark, Finland, Iceland, Norway, and Sweden. J Child Psychol Psychiatry 1989; 30: 405-16.

66 Stevens MC, Fein DH, Waterhouse LH. Season of birth effects in autism. J Clin Exp Neuropsychol 2000; 22: 399-407.

67 Torrey EF, Dhavale D, Lawlor JP, Yolken RH. Autism and head circumference in the first year of life. Biol Psychiatry 2004; 56: 892-4.

68 Torrey EF, Hersh SP, McCabe KD. Early childhood psychosis and bleeding during pregnancy. A prospective study of gravid women and their offspring. J Autism Child Schizophr 1975; 5: 287-97.

69 Tsai LY, Stewart MA. Etiological implications of maternal age and birth orde in infantile autism. J Autism Dev Disord 1983; 13: 57-65.

70 Wilkerson DS, Volpe AG, Dean RS, Titus JB. Perinatal complications as predictors of infantile autism. Int J Neurosci 2002; 112: 1085-98.

71 Yeates-Frederikx MH, Nijman H, Logher E, Merckelbach HL. Birth patterns in mentally retarded autistic patients. J Autism Dev Disord 2000; 30: 257-62.

72 Zambrino CA, Balottin U, Bettaglio E, Gerardo A, Lanzi G. Obstetrical suboptimality in autistic children: An Italian sample. J Autism Dev Disord 1997; 27: 493-4

73 Zwaigenbaum L, Szatmari P, Jones MB, Bryson SE, MacLean JE, Mahoney WJ. Pregnancy and birth complications in autism and liability to the broader autism phenotype. J Am Acad Child Adolesc Psychiatry 2002; 41: 572-9.
74 DerSimonian R, Laird N. Meta-analysis in clinical trials. Control Clin Trials 1986; 7: 177-88.

75 Takkouche B, Cadarso-Suarez C, Spiegelman D. Evaluation of old and new tests of heterogeneity in epidemiologic meta-analysis. Am J Epidemiol 1999; 150: 206-15.

76 Greenland S, Longnecker MP. Methods for trend estimation from summarized dose-response data, with applications to meta-analysis. Am J Epidemiol 1992; 135: 1301-9.

77 Sterne JAC, Bradburn MJ, Egger M. Meta-analysis in stata. In Systematic Reviews in Health Care: Meta-analysis in Context (eds M Egger, GD Smith, DG Altman): 86-95. BMJ Publishing Group, 2006.

78 Higgins JP, Thompson SG, Deeks JJ, Altman DG. Measuring inconsistency in meta-analyses. BMJ 2003; 327: 557-60.

79 Sharp S. Meta-analysis regression. Stata Technical Bulletin 1998; 42: 16-24.

80 Stram DO. Meta-analysis of published data using a linear mixed-effects model. Biometrics 1996; 52: 536-44.

81 Khoshdel A, Attia J, Carney SL. Basic concepts in meta-analysis. A primer for clinicians. Int J Clin Pract 2006; 60: 1287-94.

82 Begg CB, Mazumdar M. Operating characteristics of a rank correlation test for publication bias. Biometrics 1994; 50: 1088-101.

83 Egger M, Smith GD, Schneider M, Minder C. Bias in meta-analysis detected by a simple, graphical test. BMJ 1997; 315: 629-34.

84 Sterne JAC, Gavaghan D, Egger M. Publication and related bias in metaanalysis: power of statistical tests and prevalence in the literature. $J$ Clin Epidemiol 2000; 53: 1119-29.

85 Rosenthal AN, Paterson-Brown S. Is there an incremental rise in the risk of obstetric intervention with increasing maternal age? Br J Obstet Gynaecol 1998; 105: 1064-9.

86 Ezra $Y$, McParland $P$, Farine D. High delivery intervention rates in nulliparous women over age 35. Eur J Obstet Gynecol Reprod Biol 1995; 62: 203-7.

87 Kazmaura MR, Lie RT. Down's syndrome and paternal age in Norway. Paedaitr Perinat Epidemiol 2002; 16: 314-9.

88 Tang $\mathrm{C}$, Wu M, Liu J, Lin H, Hsu C. Delayed parenthood and the risk of Cesarean delivery - is paternal age an independent risk factor? Birth 2006; 33: $18-26$.

89 Jones MB, Szatmari P. Stoppage rules and genetic studies of autism. J Autism Dev Disord 1988; 18: 31-40.

90 Gillberg C, Schaumann H, Gillberg IC. Autism in immigrants: children born to in Sweden to mothers born in Uganda. J Intellect Disabil Res 1995; 39; 141-4.

91 Previc FH. Prenatal influences on brain dopamine and their relevance to the rising incidence of autism. Med Hypotheses 2007; 68: 46-60.

92 Ben-Haroush A, Yogev Y, Hod M. Epidemiology of gestational diabetes mellitus and its association with type 2 diabetes. Diabet Med 2004; 21: 103-13.

93 Catalano PM, Kirwan JP, Haugel-de Mouzon S, King J. Gestational diabetes and insulin resistance: Role in short- and long-term implications for mother and fetus. J Nutr 2003; 133: s1674-83.

94 Eidelman Al, Samueloff A. The pathophysiology of the fetus of the diabetic mother. Semin Perinatol 2002; 26: 232-6.

95 Biri A, Onan A, Devrim E, Babacan F, Kavutcu M, Durak I. Oxidant status in maternal and cord plasma and placental tissue in gestational diabetes. Placenta 2006; 27: 327-32.

96 Martin JA, Hamilton BE, Ventura SJ, Menacker F, Park MM. Births: final data for 2000. Natl Vital Stat Rep 2002; 50: 1-101.

97 Stroup DF, Berlin JA, Morton SC, Olkin I, Williamson GD, Rennie D, et al. Meta-analysis of observational studies for epidemiology: a proposal for reporting. JAMA 2000; 283: 2008-12. 